\title{
Digital learning innovation on concept development course. A study in visual communication design program at Universitas Ciputra
}

\author{
L. Indriati \\ Universitas Ciputra, Surabaya, Indonesia
}

\begin{abstract}
Online learning becomes an obligation that must be undertaken by higher education during the Covid-19 pandemic. For this reason, it is necessary to adapt to technology and the learning process so that the quality of education in Indonesia can continue to improve even though delivered online. This study using a case study of online learning in the Concept Development course. This study uses a mixed-methods, by surveying a survey of 49 students of Visual Communication Design Universitas Ciputra deepened with interviews. The results of this study get recommendations for digital learning innovations that are appropriate when viewed from the TPACK framework from the aspects of technology, pedagogy, and content. Analysis of the survey results and interview resulted in several digital learning innovations that will apply in the future, including a personality assessment test, real user experience, and collaborative asynchronous learning.
\end{abstract}

Keywords: TPACK, Technology, Pedagogy, Content, Innovation, Online Learning

\section{BACKGROUND}

The application of information and communication technology in the development of today's education is a must, especially during the Covid-19 pandemic. Educational technology becomes very crucial as the only medium that can help the learning process at this time. All levels of education are required to adapt to technology and the learning process. Not only applying technology but also maintaining the quality of learning even though the material is delivered online.

The main problem in the world of education in the globalization era is the low level of quality, innovation, and human resources. According to Forlab Dikti data, the reality of the number of Higher Education Institutions in Indonesia is around 4,695 Universities (1,064 Academies, 278 Polytechnics, 2,534 Colleges, 217 Institutes, 583 Universities, 19 Community Colleges). A large number of tertiary institutions cause the unfocused field of science to be studied, resulting in the low quality of learning, research, and publications produced by educational institutions. To lessen the gap, digital learning innovations will be applied to Concept Development courses to prepare students for social, cultural, workplace, and technological advancements.

\section{RESEARCH METHOD}

The research method used in this study is a mixed-method, which combines the two approaches in research, namely, qualitative and quantitative (Creswell 2015: 5). The selected mixed method is a sequential explanatory design that is a research model characterized by collecting data and analyzing quantitative data in the first stage and followed by collecting and analyzing qualitative data in the second stage, to strengthen the results of quantitative research conducted in the first stage (Sugiyono 2011: 409).

This strategy is carried out quantitatively by survey methods. The survey was distributed to 49 respondents and analyzed descriptive statistics. According to Sugiyono (2012: 13), descriptive 

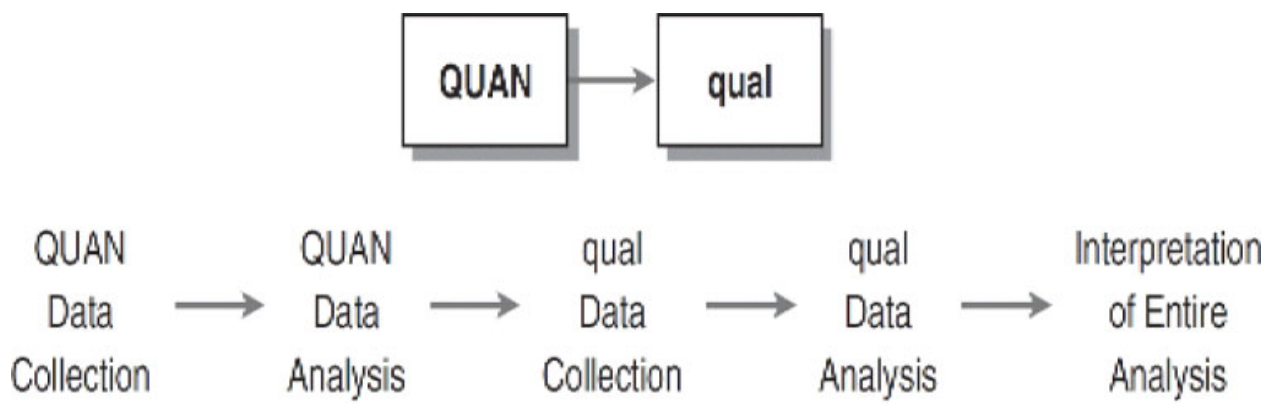

Figure 1. Sequential explanatory design.

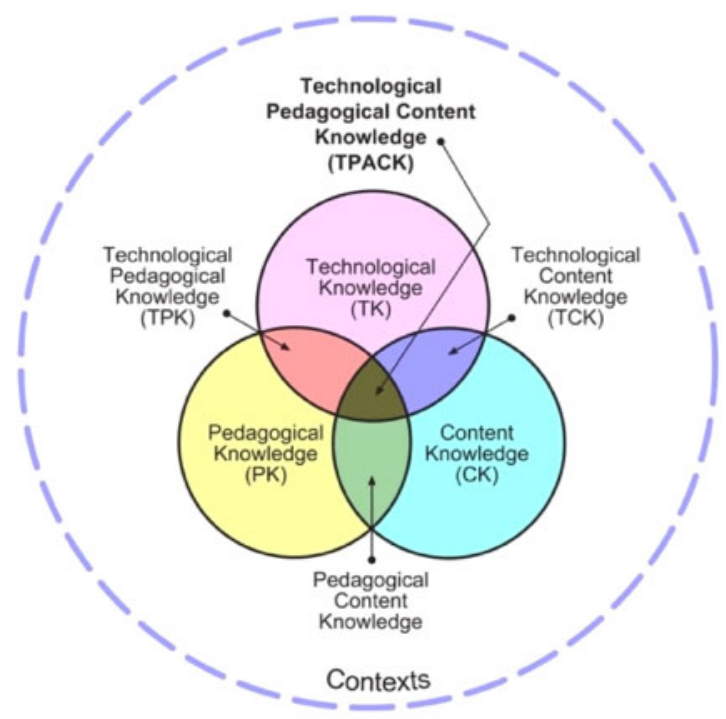

Figure 2. Framework TPACK.

research is research conducted to determine the value of an independent variable, either one variable or more (independent) without making the comparison, or connecting with other variables. In the second phase, the quantitative data obtained deepen through interviews with students associated with the study of literature about the design process and development of online courses. The framework used in this research is the TPACK (Technological Pedagogical Content Knowledge) framework, which considers three main aspects: technological, pedagogical, and content aspects (Kaplon-Schilis \& Lyublinskaya 2020: 25-43).

\section{DISCUSSION}

Concept Development courses aim to provide an understanding of the theory and practice of the process of coordinating and directing design resources to be able to solve problems that occur. After attending this course, students are expected to be able to use design as a management tool to determine and achieve strategic goals. Based on the survey of 49 students the following is a description of the results obtained: 
Table 1. Lecturer evaluation by students survey.

\begin{tabular}{llccc}
\hline & N & Min & Max & Average \\
\hline Course quality & 49 & 3 & 5 & 4,2 \\
Material quality & 49 & 2 & 5 & 4,1 \\
Presentation & 49 & 2 & 5 & 4,3 \\
Answering question & 49 & 3 & 5 & 4,4 \\
Express opinions & 49 & 2 & 5 & 3,9 \\
Assignments & 49 & 1 & 5 & 4,2 \\
\hline
\end{tabular}

Source: processed secondary data 2020.

From the interview with the students who took the Concept Development course, the following results obtained:

The results of the analysis in the table above produce several insights to apply in the future. The recommendations for digital learning innovation include:

Table 2. Interview.

\begin{tabular}{ll}
\hline TPACK & DESCRIPTION \\
\hline Technology & Adding translation to a presentation \\
- More playful and interactive \\
- Honestly online class is making this course a tough one... \\
- Use slideshow as presentation of material cause people was too lazy to watch material \\
from Youtube (as Youtube is for entertainment, not for study purposes, when we look \\
at Youtube algorithm) \\
- Tasks that directly work together to help with clients \\
- A bigger group discussion to switch minds and opinions would be great \\
- More personal activities \\
- All that is gained from this learning though it feels fast to understand the steps for this \\
semester but from here, I hope to continue to get learning related to the client so that \\
- he can understand when meeting with clients in the future \\
- Know how to create a structural concept \\
- Maybe invite some people to tell their experience that can be related to this class. \\
- Conducting guidance on getting used to students doing research is good. But I feel it \\
would be better if it was further deepened on how to do research and technical market \\
- Explain more about the purpose and giving tips and tricks to help understand the material \\
- Overall I think this class is helping us to know the client's businesses or our businesses \\
way better and improving the skill that we can use in the future! In the end, I really enjoy \\
this class.
\end{tabular}

\subsection{Personality assessment test}

The user or client expects the designer to be creative, but often what the designer does not realize is that the client also expects the designer to be confident and able to manage the entrusted project well. Therefore, at the beginning of the lecturing session, students will be given a personality assessment quiz that aims to find out each strength so that they can maximize team performance. Taking the concept of team formation in the startup business, the skills needed in a team are at least three types of people: hacker (developer), hipster (designer), and hustler (communicator) (Medium.com 2018). Through this assessment, students expected to make team formations that can complement each other in impressive ways (Bakan \& Bakan 2018: 119-145). 


\subsection{Real user experience}

Students who took the Concept Development course are expected to have holistic abilities in applying design as a real-world problem-solving tool. Therefore, this course presents partners from the industry as real clients with real problems as case studies for students. The purpose of inviting clients is to foster student confidence through the opportunity to make decisions in designing and presenting the idea in front of real clients (Coleman et al. 2016). Thus, students are expected to be able to explain the design concept, why use the design approach, and how the idea can answer the client's needs. This method can also train students' soft skills in managing a design project, such as how they present design concepts and how to answer questions raised by clients. Besides, by introducing students to real clients, they are expected to be able to open opportunities and build their connections to the internship program or even get a job. The learning scheme by involving partners is as follows:

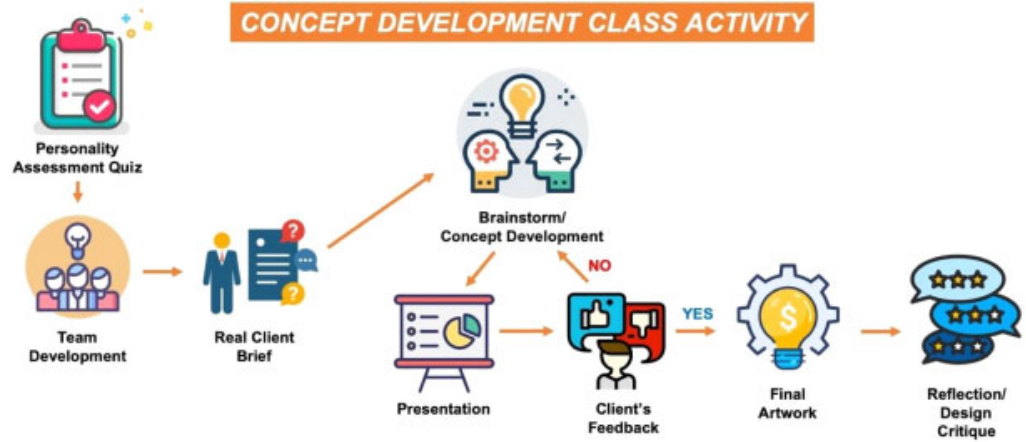

Figure 3. Concept Development course learning activity.

\subsection{Collaborative asynchronous learning}

This course will apply the learning flexibility with asynchronous learning, collaboration, and multiplatform. Students can still study the subject even though the connection access barriers or conflicting schedules with courses or activities at each campus. The obstacle when carrying out collaborative learning experiences in online learning is when there are limitations to carrying out asynchronous interactions (Hafner \& Ellis 2004). For example, students from other universities who take this course and have conflicting class schedules can still learn by watching the learning videos provided by the lecturer. Besides, each week will have periodic assignments that will be

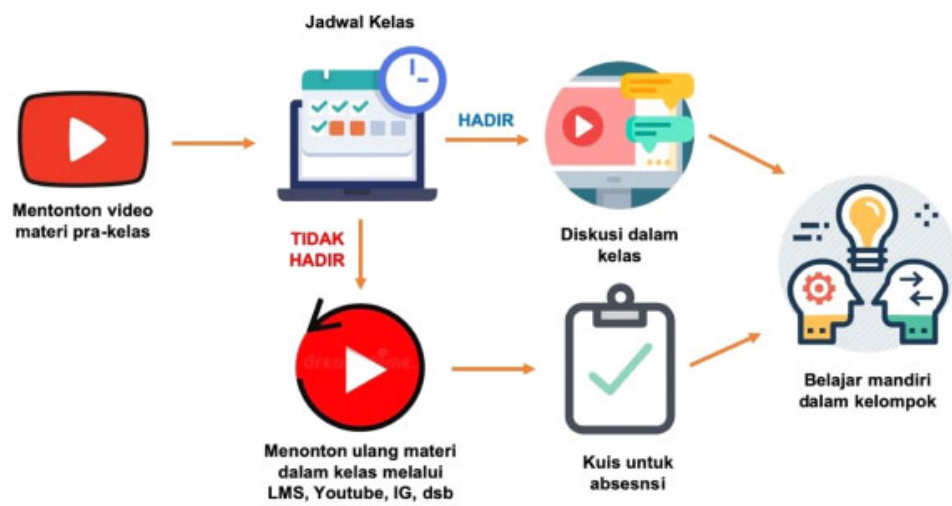

Figure 4. Collaborative asynchronous learning method on Concept Development course. 
compiled at a certain as proof of attendance. All material, modules, worksheets used in this course will be uploaded through the Learning Management System (LMS), or other media to facilitate easy access for students. Video material uploaded on YouTube or Instagram, worksheets are shared via email or group chat, presentations through Zoom Meeting media, and so on.

\section{CONCLUSION}

Based on the results and discussion above, the conclusion is as follows:

1. Digital learning innovations carried out mainly for creative subjects are expected to meet technological, pedagogical, and content aspects such as the TPACK framework to produce ideal online learning innovations.

2. The use of technology and social media can help students feel that courses are more accessible and flexible in using various platforms so that they can be more engaged in online learning

3. Innovations generated in this study, also can be applied to other subjects within the scope of the Visual Communication Design program whose application needs to be adjusted to the learning achievements of each course.

\section{ACKNOWLEDGEMENT}

The researcher would like to thank especially the respondents, students of Visual Communication Design Universitas Ciputra class of 2018 which were willing to fill out the survey and were interviewed for this research.

\section{REFERENCES}

Archambault, L.M. \& Barnett, J.H., 2010. Revisiting technological pedagogical content knowledge: Exploring the TPACK framework. Computers \& Education, 55(4), pp. 1656-1662.

Bakan, U. \& Bakan, U., 2018. Game-based learning studies in education journals: A systematic review of recent trends. Actualidades Pedagógicas, 72(72), pp. 119-145.

Coleman, R., Clarkson, J.. \& Cassim, J., 2016. Design for inclusivity: A practical guide to accessible, innovative and user-centred design. CRC Press.

Guetterman, T.C., Fetters, M.D. \& Creswell, J.W., 2015. Integrating quantitative and qualitative results in health science mixed methods research through joint displays. The Annals of Family Medicine, 13(6), pp. 554-561.

Hafner, W. \& Ellis, T.J., 2004, October. Asynchronous collaborative learning using project-based assignments. In 34th Annual Frontiers in Education, 2004. FIE 2004. (pp. F2F-6). IEEE.

Kaplon-Schilis, A., \& Lyublinskaya, I. (2020). Analysis of Relationship Between Five Domains of TPACK Framework: TK, PK, CK Math, CK Science, and TPACK of Pre-service Special Education Teachers. Technology, Knowledge and Learning, 25(1), 25-43.

Koehler, M. \& Mishra, P. (2009). What is Technological Pedagogical Content Knowledge (TPACK)? Contemporary Issues in Technology and Teacher Education, 9(1), 60-70. Waynesville, NC USA: Society for Information Technology \& Teacher Education.

Yargın, G.T., Süner, S. \& Günay, A., 2018. Modelling user experience: Integrating user experience research into design education. 